This item was submitted to Loughborough's Research Repository by the author.

Items in Figshare are protected by copyright, with all rights reserved, unless otherwise indicated.

\title{
Early algebraization: a global dialogue from multiple perspectives (book review)
}

PLEASE CITE THE PUBLISHED VERSION

http://dx.doi.org/10.1080/14794802.2012.734996

PUBLISHER

Routledge (Taylor \& Francis Group) / @ lan Jones

VERSION

AM (Accepted Manuscript)

LICENCE

CC BY-NC-ND 4.0

REPOSITORY RECORD

Jones, lan. 2019. "Early Algebraization: A Global Dialogue from Multiple Perspectives (book Review)". figshare. https://hdl.handle.net/2134/12553. 
This item was submitted to Loughborough's Institutional Repository (https://dspace.lboro.ac.uk/) by the author and is made available under the following Creative Commons Licence conditions.

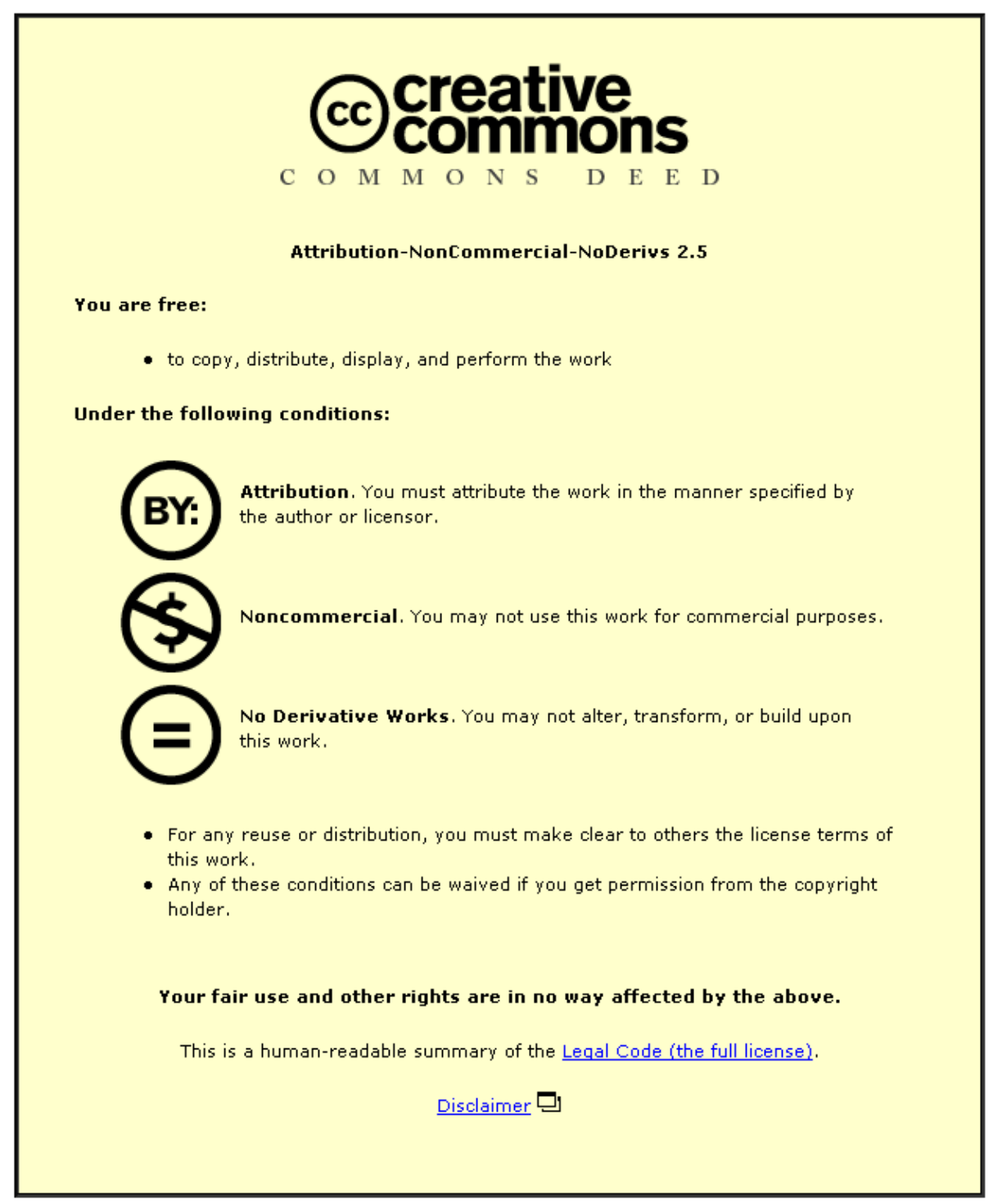

For the full text of this licence, please go to: http://creativecommons.org/licenses/by-nc-nd/2.5/ 
Early algebraization: a global dialogue from multiple perspectives, edited by Jinfa Cai and Eric Knuth, Heidelberg, Springer, 2011, 623 pp., £78.60 (hardback), ISBN: 978-3642177347

Research into how children come to learn algebra can be traced back over three decades, and nowadays studies into "early algebra" are common, particularly in the US. This body of research has impacted on mathematics education practice too, at least to some extent. Many countries around the world, for example New Zealand and China, have incorporated early algebraic activities into their primary and early secondary curricula and pedagogy, while others, for example the US and UK, are sluggish to do so.

\section{Early Algebraization: A Global Dialogue from Multiple Perspectives offers a} collection of revised journal articles and original contributions on research into young children's acquisition of algebraic modes of thinking. It is divided into three sections offering curricular, cognitive and instructional perspectives, with summarising chapters at the end of each section and an overall commentary by Carolyn Kieran at the conclusion of the book. Many contributions could sit easily in more than one section, and several of the cognitive chapters in particular carry an explicit curricular or instructional focus.

Two contributors who help clarify the nature of algebraic thinking and its precursors are Mason and Radford. Mason's well-known motto "seeing the general in the particular" is cited by several contributors, and is the focus of chapters describing young children working with pattern sequences. However, both Mason and Radford caution that not all generality is algebraic. Radford argues there is nothing algebraic about identifying pattern sequences unless it involves dealing with indeterminacies in an analytical way. Mason concurs, offering a view of algebra as a language for dealing systematically with "the as-yet unknown" (559). Both authors see the roots of algebraic thinking in early awarenesses of discrimination and generalisation of stimuli and actions. Many contributors emphasise the importance of quantities and the relationships between them for thinking algebraically. For some, such as Moss and London $\mathrm{McNab}$, and Ellis, quantities and relationships underlie contextualised "functional" activities in which students work with covariational relationships embodied in physical and pictorial representations such as gears and geometric patterns. For others, such as Empson, Levi and Carpenter, quantities and relations underlie abstract "relational thinking" with formal symbol systems.

There is a notable lack of consensus on the role of formal symbols in learning algebra. Radford argues that alphanumeric symbols "are neither a necessary nor sufficient condition for thinking algebraically" (310). Siraman and Lee define early algebraization as "pattern finding and relationships in the curriculum without the formalism of notation or symbols" (368), and consider this the consensus view among mathematics educators. Others, including Cai and colleagues, and Ellis, present evidence that children can struggle to express their understanding using formal notation when first learning algebra, and argue for contextualised and functional approaches as a foundation for later formalism. However the picture is mixed. Blanton and Kaput, Empson and colleagues, and Izsacks contribute evidence that children can learn about and with formal notation from a young age. Perhaps the most 
radical and intuitively appealing approach in the book, the Davydovian curriculum as presented by Schmiteau, advocates the introduction of symbolised relations between pictorial and symbolic quantities at the start of primary school.

Overall the book leaves the strong impression that the dubious reputation of formal symbols in the primary classroom arises from inappropriate pedagogy and resources rather than from young children's lack of ability (see also Kirshner 2001). As Mason points out, pre-school children already display "the requisite powers to make use of algebra as a language of expression of relationships" (564). As such, approaches that omit or delay formal symbolism can be limited. For example, Rivera and Becker examine how students constructed and justified algebraic representations of generalised patterns. Equation construction and justification are important algebraic activities, but these activities stop where another essential ingredient of algebra begins, that is dropping context at least temporarily in order to explore quantitative relationships and properties in a systematic and thorough manner. Dörfler (2006) has argued that conventional notation can be a powerful medium for mathematical learning through creative experimentation with formal symbol systems and their rules for making transformations. In this way abstract mathematics is experienced as a material activity of meaningful actions on symbols. Persuasive empirical examples consistent with this view can be seen in Empson and colleagues, and also in Hewitt (2012).

To disentangle and properly understand the roles of contextualisation and symbolism in the development of algebraic thinking requires theoretical accounts and empirical evidence. Some authors present comparative evidence although it can be hard for the reader to draw firm conclusions. For example, Cai and colleagues compare the learning outcomes of a functional curriculum, in which covariational relationships are expressed by, for example, geometric patterns, with a structural curriculum, in which quantitative relationships are expressed by symbolic equations. Students studying the functional curriculum performed better at representing and generalising covariational relationships, but the difference appears small if significant. The authors report that the functional curriculum was taught "conceptually" and the structural one "procedurally", making it difficult to untangle the results. However structural curricula need not be taught in a procedural way. Britt and Irwin report that children in New Zealand following an innovative (conceptual and structural) curriculum outperformed those following a traditional curriculum, although the margin of difference between the groups is not reported. Schmiteau summarises a markedly better performance of children following a Davydovian (conceptual and structural) curriculum compared to children following a traditional curriculum in the US, although the results are not presented in detail.

A rigorously presented study is Knuth and colleagues' investigation into the role of understanding equivalence and variable on algebraic equation solving and interpretation. However the study, which has clear practical implications, lacks theoretical detail. This is a disappointment in light of the research team's impressive contribution to theory on the development of algebraic concepts elsewhere (e.g. McNeil et al., 2011). Conversely, many chapters are explicitly theory-based, and many authors exemplify their theoretical approach with excerpts from curricula, resources, classroom episodes and interview transcripts. The range of approaches is eclectic as reflected by the term "multiple perspectives" in the book's subtitle. For 
example Izsák extends "representational competence" to the case of algebraic modelling, Morselli and Boero interpret students' algebraic proving and modelling using Habermas' theory of rational behaviour, Schmiteau draws on Vygotsky's developmental model of the abstract preceding the concrete, and Li, Peng and Song explain a Chinese approach to teaching equations using "a theory of teaching with variations" (531). In each of these four examples a general education theory is applied to algebraic thinking and learning. Similarly, throughout the book a range of general theories are used by different authors to help understand and explain early algebraic activity.

One exception to this theoretical generality is the chapter by Empson and colleagues in which the early algebra-specific theoretical idea of relational thinking is presented. Empson and colleagues define relational thinking as "children's use of fundamental properties of operations and equality to analyse a problem in the context of a goal structure and then to simplify progress towards this goal" (411). Relational thinking is a theoretical tool that has been developed over several years' empirical work by the authors, and is used to demonstrate and explain a structural approach in which young children use formal arithmetic notation as a tool for solving fraction problems. This seems a promising way forward and offers a foundation for building further theory about the development and promotion of algebraic thinking in primary classrooms.

Overall, however, I was left with the sense of a discipline that is fragmented rather than enriched by the multiple perspectives adopted. In the remainder of the review I consider future directions that might lead to a more unified theoretical account, and a more cumulative body of evidence.

It seems there are now sufficient published data and findings for a systematic metareview to be undertaken as a first step to establishing what is known, and how it might be synthesised. This would be no small undertaking, and would doubtless lead to more questions and uncertainties than secure findings. The methods and findings reported in the book provide a helpful initial framing, although need extending. One absence is McNeil and colleagues' change-resistance account, which posits that children's difficulties with algebra arise from internal "representations of patterns routinely encountered in the first few years of formal arithmetic instruction" (2011, 1621).. For example the operational pattern leads learners to the stubborn expectation that expressions should always be computed and that an equals sign should always be followed by a result. In addition, Rittle-Johnson and colleagues' (2011) carefully evaluated construct map for the development of equivalence knowledge deserves close attention from researchers.

One research methodology that rightly receives attention in the book is the international comparison, which enables scholars to explore the impact of different approaches to early algebra in curricula and pedagogy around the world. Work by Li et al. (2008) among others suggests developmental models such as Rittle-Johnson and colleagues' construct map mentioned above are not universal. Similarly, the findings that support the change-resistance account of McNeil and colleagues are probably most applicable to Western contexts in which early algebra research has had only limited impact on primary classrooms. To progress our understanding of how children come to learn algebra it is important that international studies be driven by theoretical 
research questions in addition to describing countries' curricula and comparing the performance of student populations.

While differences between countries are explored in several chapters in the book, individual differences between learners are largely overlooked. For example, Empson and colleagues provide a convincing exemplification of relational thinking but provide no background information about the children studied. Consequently it is impossible to know the extent to which the findings might generalise to all or most young learners. Similarly, Moss and London McNab are homogenous in their description of children's learning across six classrooms, concluding broadly that the children "could predict how a pattern would grow, find general rules for geometric and numeric patterns, and construct patterns based on given rules" (295). Such homogenous summarising of children's learning can be found elsewhere in the early algebra literature. We ignore individual differences at our peril when building theory about how learners develop algebraically. For example, Gilmore and Bryant (2006) reported the surprising result that many young children display a better conceptual than procedural understanding of arithmetic equations. It should not be assumed that all or even most children will perceive or benefit from algebraic tasks in the same way.

Another important area for research is the study of longitudinal algebraic development. Radford and Mason consider the antecedents of algebra to be noticing distinctions and generalities, and reification theories view algebraic entities as objectified arithmetic (and algebraic) processes (e.g. Gray and Tall 1994). Further work is needed to understand the origins of algebraic ideas at a fine-grained level. For example, recent research has revealed increasing detail about the nature of our innate Approximate Number System (ANS) and how it might relate to learning symbolic arithmetic (Mundy and Gilmore, 2009). There is scope for early algebra scholars to draw on research into numeracy. For example, how might the ANS relate to early learning about the symbolic and non-symbolic relationships between quantities as described by Schmiteau, and Moss and London McNab?

Regarding later development, we know traditional arithmetic approaches can create barriers to subsequent learning, but little research has explored what barriers might inadvertently be created by innovative approaches to early algebra. There is a temptation to assume few barriers would arise, and some of the available evidence should give us confidence. For example, Cai and colleagues found that a functional curriculum better prepared children than a traditional curriculum for the functional activities of representing and generalising covariational relationships. However the traditional curriculum did not better prepare children for solving equations despite including substantially more equation solving practice. Analogously, McNeil et al. (2011) found that emphasising a computational view of arithmetic equations hampered young children's relational understanding, but emphasising a relational view did not hamper computational proficiency. Nevertheless, even when learners display a conceptual understanding of algebra development is unlikely to be straightforward. Filloy, Rojano and Solares (2010) showed that that children "with mid- and high-level competences" (62) at solving single-unknown equations abandoned algebraic strategies and resorted to arithmetic and natural language strategies when confronted with simultaneous equations containing two unknowns. 
Clearly the kinds of activity and understanding valued and reported by those of us researching children's early algebraization are not the end of the story.

I have not attempted to be comprehensive in this review, which would be almost impossible for an edited book totalling over 600 pages. One issue I have chosen not to discuss is that of teacher knowledge. Given that many primary teachers lack confidence with algebra it could be argued teacher knowledge is the single most pressing issue for the learning of early algebra. It is not my intent to imply otherwise by omitting it.

\section{References}

Dörfler, W. 2006. Inscriptions as objects of mathematical activities. In New mathematics education research and practice, ed. J. Maasz and W. Schloeglmann, 97-111. Rotterdam: Sense Publishers.

Filloy, E., T. Rojano, and A. Solares 2010. Problems dealing with unknown quantities and two different levels of representing unknowns. Journal for Research in Mathematics Education 41: 52-80.

Gilmore, C., and P. Bryant 2006. Individual differences in children's understanding of inversion and arithmetical skill. British Journal of Educational Psychology 76: 309-331.

Gray, E., and D. Tall. 1994. Duality, Ambiguity, and Flexibility: A "Proceptual" View of Simple Arithmetic. Journal for Research in Mathematics Education 25: 116-140.

Hewitt, D. 2012. Young students learning formal algebraic notation and solving linear equations: are commonly experienced difficulties avoidable? Educational Studies in Mathematics doi:10.1007/s10649-012-9394-X

Kirshner, D. 2001. The structural algebra option revisited. In Perspectives on School Algebra, ed. R. Sutherland, T. Rojano, A. Bell and R. Lins, 83-99. London: Kluwer Academic Publishers.

Li, X., M. Ding, M. M. Capraro, and R. M. Capraro. 2008. Sources of differences in children's understandings of mathematical equality: Comparative analysis of teacher guides and student texts in China and the United States. Cognition and Instruction 26: 195-217.

McNeil, N. M., Fyfe, E. R., Petersen, L. A., Dunwiddie, A. E., and Brletic-Shipley, H. (2011). Benefits of practicing $4=2+2$ : nontraditional problem formats facilitate children's understanding of mathematical equivalence. Child Development, 82, 1620-1633.

Mundy, E. and C. Gilmore. 2009. Children's mapping between symbolic and nonsymbolic representations of number. Journal of Experimental Child Psychology 103: 490-502.

Rittle-Johnson, B., R. Taylor, P. Matthews, and K. McEldoon. 2011. Assessing Knowledge of Mathematical Equivalence: A Construct Modeling Approach. Journal of Educational Psychology 103: 85-104. 